\title{
Erratum to: One-year follow-up of mud-bath therapy in patients with bilateral knee osteoarthritis: a randomized, single-blind controlled trial
}

\author{
A. Fioravanti • G. Bacaro • C. Giannitti • S. Tenti • \\ S. Cheleschi • G. M. Guidelli • N. A. Pascarelli • \\ M. Galeazzi
}

Published online: 18 March 2015

(C) ISB 2015

Erratum to: Int J Biometeorol

10.1007/s00484-14-0943-0

The correct spelling of the 6th author's name is G.M. Guidelli.

The online version of the original article can be found at http://dx.doi.org/ 10.1007/s00484-14-0943-0.

A. Fioravanti $(\bowtie) \cdot$ C. Giannitti $\cdot$ S. Tenti $\cdot$ S. Cheleschi $\cdot$

G. M. Guidelli • N. A. Pascarelli • M. Galeazzi

Rheumatology Unit, Department of Medicine, Surgery and

Neurosciences, University of Siena, Policlinico "Le Scotte," Viale

Bracci 1, 53100 Siena, Italy

e-mail: fioravanti7@virgilio.it

G. Bacaro

CNR-IRPI, Istituto di Ricerca per la Protezione Idrogeologica, Via

Madonna Alta 126, 06128 Perugia, Italy

G. Bacaro

BIOCONNET, Biodiversity and Conservation Network, Department

of Life Sciences, University of Siena, Via PA Mattioli 4,

53100 Siena, Italy 